\title{
Performance of Concrete Overlays in lowa
}

\author{
Peter Taylor ${ }^{1, *}$, Jerod Gross $^{2}$, Dan $\mathrm{King}^{3}$, Yu-An $\mathrm{Chen}^{1}$, and Halil Ceylan ${ }^{1}$ \\ ${ }^{1}$ Iowa State University, Iowa, USA \\ ${ }^{2}$ Snyder and Associates, Ankeny, Iowa, USA \\ ${ }^{3}$ Iowa Concrete Paving Association, Ankeny, Iowa, USA
}

\begin{abstract}
It has often been claimed that concrete overlays are a cost effective, low maintenance preservation tool used to extend pavement life. However, there has been relatively little data to confirm this. The State of Iowa has a long history of using concrete overlays as a means of extending the life of all types of roadways and as such provides an interesting opportunity to examine their performance over time. The work described in this paper summarizes the activities and findings of a study conducted for the Iowa Highway Research Board. Existing databases operated by the Department of Transportation and Iowa State University were analyzed to assess the performance of overlays. Pavement condition data such as IRI, transverse cracking, longitudinal cracking, Dcracking, spalled joints and faulting were compared with design details of the overlays such as bond type, thickness and joint spacing. The data indicate that in general overlay performance is very good in that about $90 \%$ of $3100 \mathrm{~km}$ of overlays are still in acceptable condition at ages up to 35 years. The paper discusses the details behind this finding.
\end{abstract}

\section{Introduction}

A previous presentation at this conference discussed the potential benefits of using concrete overlays as a means of extending the life of existing pavements of all types [1]. These benefits include effective use of the investment already made in to the existing system, improved sustainability by minimizing the thickness of the new surface layer, and reduced impact to the public by avoiding the time needed to rework the foundation layers.

A common question has been based on a concern about the longevity of such systems and potential failure modes.

Recent work conducted by Iowa State University included a review of the performance data of the $\sim 3100$ $\mathrm{km}$ of overlays still in use in Iowa. The study included overlays constructed over the last 40 years using a variety of bonding systems, thicknesses and panel sizes on city, county and state roadways [3].

In general, about $90 \%$ of the data points are still exhibiting satisfactory performance. The systems that did exhibit premature distress were investigated in more detail and the causes were found to be similar to those observed in conventional concrete pavements.

\section{Overview}

The National Concrete Overlay Explorer is an online database of concrete overlays constructed throughout the US (Figure 1)[2]. It is likely that the data in this reference have not been kept up to date - so the numbers quoted may be considered conservative. Some 1300 overlay projects are recorded.

Some interesting observations include records of overlays built as early as 1901 demonstrating that this is not a new technology. The earliest reported overlay still in service was constructed in 1960 in Iowa and is in fair condition although it has been heavily patched. In the early years of development and implementation of concrete overlays, expected service life was approximately 20 years [4].

\section{Data}

As can be seen in Figures 1 and 2, a significant number of overlays have been constructed in Iowa, making this an ideal location to conduct a representative review of longterm performance. In addition, good records have been collected over time about the pavements, albeit by different agencies.

\subsection{Data Sources}

One source of data was the Iowa DOT, which has collected pavement condition data on all paved secondary roads since 2002 and on every paved public roadway in Iowa since 2013. Data collected includes international roughness index (IRI), transverse cracking, longitudinal cracking, D-cracking, spalled joints, and faulting.

* Corresponding author: ptaylor@iastate.edu 


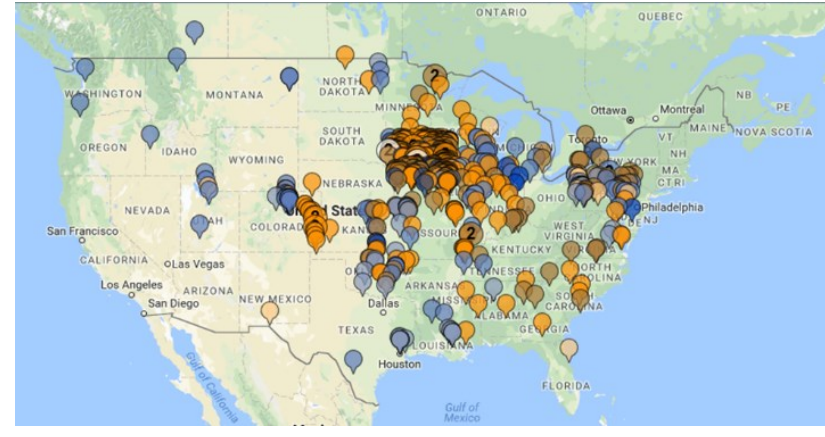

Figure 1. Overlays built in the US [2]

The Institute for Transportation (InTrans) at Iowa State University manages the state pavement condition data set as part of the Iowa Pavement Management Program (IPMP).

The Iowa Concrete Pavement Association also has an extensive database of construction-based information for overlays constructed within Iowa that includes 521 concrete overlays totalling more than 3100 centreline $\mathrm{km}$ (Figure 2).

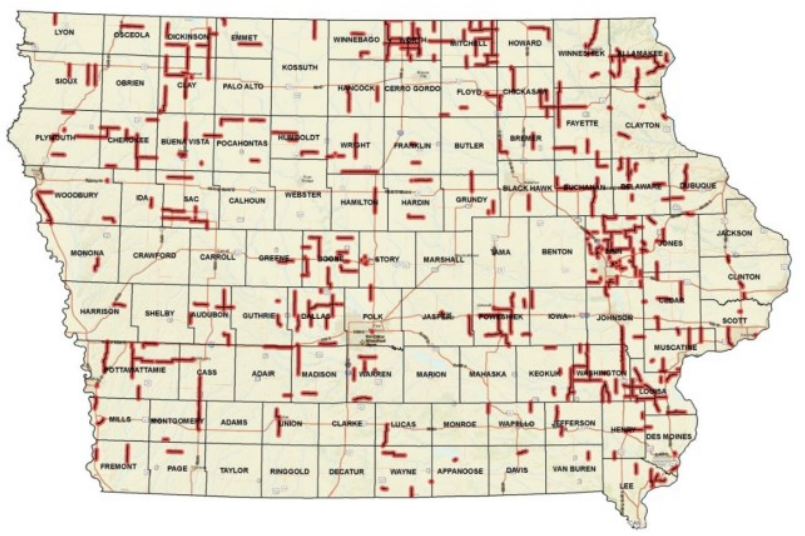

Figure 2. Locations of Overlays in Iowa [3]

\subsection{Data Handling}

A challenging step in the work was combining the different data sets, including resolving differences in definitions (such as bonded vs unbonded). The data sets were linked together by assigning longitude and latitude coordinates for the beginning and end of each project location as well as assigning a unique project identifier to each project.

The next step was to review the quality of the data and to remove or resolve instances of irrelevant, inaccurate, or incomplete records. Some of the incomplete information was obtained from the relevant owner agencies. Incomplete projects were removed from the database. Other examples removed from the data set were pavements that were research projects; reported to have failed in less than a year (likely incorrect data); removed from service at an unknown time; or those rehabilitated with no records.

After filtering the data, the final database described 384 concrete overlay projects totalling $2400 \mathrm{~km}$, and average project length of $\sim 6.3 \mathrm{~km}$.
Data records included:

- Overlay type (bonded/unbonded on concrete/asphalt)

- Location (county/city)

- Project number

- Road name and description

- Length

- Latitude and longitude of project limits

- Overlay construction year

- Overlay thickness

- Transverse joint spacing

- Traffic count

- International Roughness Index

- Transverse cracking

- Longitudinal cracking

- Transverse joint faulting

- D-cracking

- Transverse joint spalling

- $\quad$ Patching

Two performance parameters (PCI and IRI) were used to assess overall pavement condition.

\subsection{Data Analysis}

The data were analysed by grouping the overlays by:

- $\quad$ Overlay type (BOA, BOC, UBOA, UBOC)

- Overlay age

- Overlay thickness

- Transverse joint spacing

The overlay types were categorized as

- Bonded on concrete (BOC) $\sim 3 \%$ of projects

- Unbonded on concrete (UBOC) $\sim 33 \%$ of projects

- Bonded on asphalt (BOA) $\sim 46 \%$ of projects $(\leq 6$ " thick)

- Unbonded on asphalt (UBOA) $\sim 18 \%$ of projects (>6" thick)

The Pavement Condition Index (PCI) is based on a rating scale from 0 to 100 with 100 representing a new pavement with no distress and 0 representing a failed pavement. A PCI rating of 60 or higher is considered good or excellent. PCI was calculated based on the amount of transverse cracking, D-cracking, joint spalling, and the IRI as shown in Equation 1. The weightings are based on experience of local agencies.

$\mathrm{PCI}=100-35(\mathrm{IRI} / 253)$

25((\# of D-Crack joints per $160 \mathrm{~m}) / 8)$ -

15((\# spalled joints per $160 \mathrm{~m}) / 9)-$

25((\#transverse cracks per $160 \mathrm{~m}) / 14)$

The IRI is commonly used to describe roughness [5] where a rating of $<95$ is considered "good" and $>\sim 3000$ $\mathrm{mm} / \mathrm{km}$ is "unacceptable".

A separate analysis was conducted to investigate faulting of BOA pavements. Records were only available where individual joints were found to have faulted greater than a threshold of $0.3 \mathrm{~mm}$. and the number of faulted 
joints per project was counted and classified. The analysis showed that a low percentage of joints exhibited faulting, and the majority were of low severity $(0.3$ to $0.6 \mathrm{~mm})$. It was concluded that faulting of bonded overlays is minimal and is not perceived as a problem.

Although traffic was initially included as a parameter, it was found that the majority of overlays had low traffic volumes because a majority of the overlays were on the secondary road system. Among all the overlays, 87\% carried 2,000 vehicles per day or fewer. This made analysis based on this factor of limited benefit.

\section{Results and Discussion}

Slab thickness varied from 100 to $250 \mathrm{~mm}$ with about half of the projects at $150 \mathrm{~mm}$. Joint spacing varied from 1.5 to $12 \mathrm{~m}$ with about half at 4.5 to $6.0 \mathrm{~m}$.

About $90 \%$ of the pavements reviewed had a PCI greater than 60 and an acceptable IRI. Figure 3 illustrates the complete set of data showing PCI as a function of time. Note that several data points may be from a single project sampled at various ages. The $\sim 1200$ data points reported here come from 384 projects.

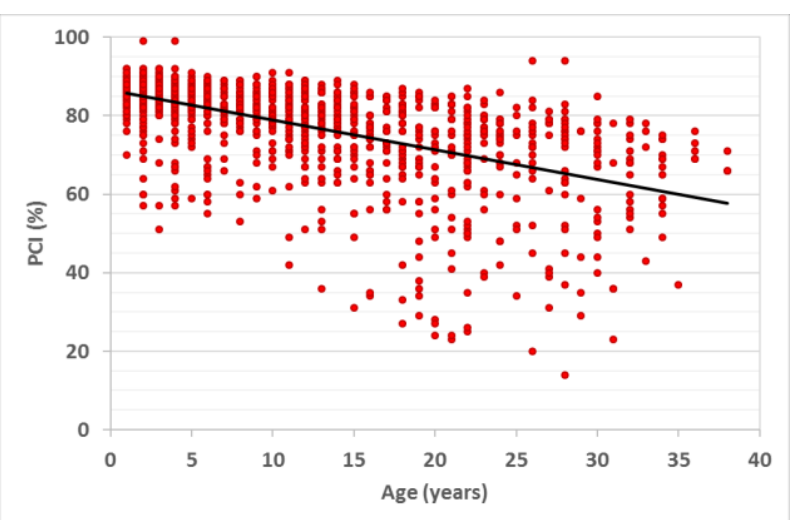

Figure 3. PCI data for all overlays as a function of time

The bulk of the systems follow a similar trend predicting an average life of about 35 years - almost double the design life of 20 years. There is a small $(\sim 5 \%)$ but notable set of pavements that have deteriorated faster than typical. Some of the poorer-performing overlays were visited to investigate the cause behind the premature failure. Three different causes were identified, none of which are unique to overlays:

- Material-related distress tied to the $\mathrm{w} / \mathrm{cm}$ and or the air void system

- Structural failure likely due to inadequate thickness or support

- Inadequate drainage

The data in Figure 3 have been split by type (bonded/unbonded) and base system (asphalt / concrete). They indicate that the unbonded systems are performing better than the bonded, and those placed on asphalt are lasting longer than those on concrete (Figure 4). These trends may be biased because the data set for $\mathrm{BOC}$ is significantly smaller, although it is acknowledged that achieving a sound bond with concrete can be a challenge.

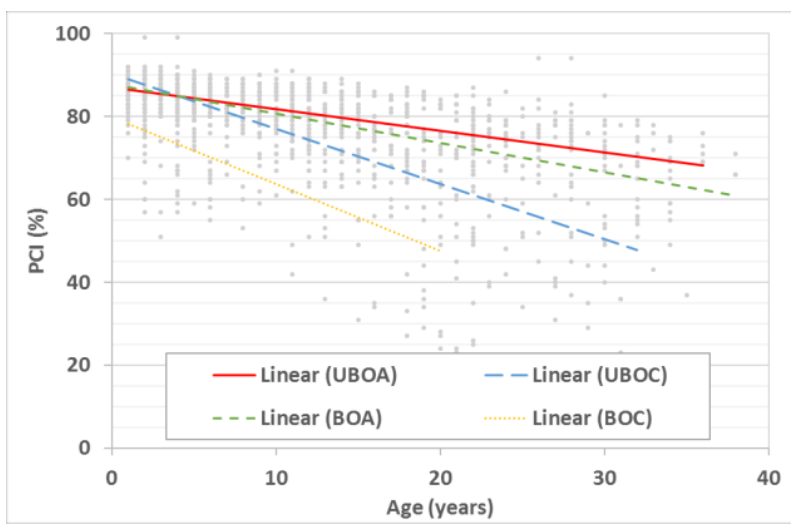

Figure 4. PCI data showing trend lines for different overlay types

The data in Figure 3 were also split by joint spacing. Relatively little effect of joint spacing is observed (Figure 5 ). About $6 \%$ of the pavements were built using spacings of $2 \mathrm{~m}$ or less and the oldest of this size has been in use for 12 years - also potentially skewing the observations.

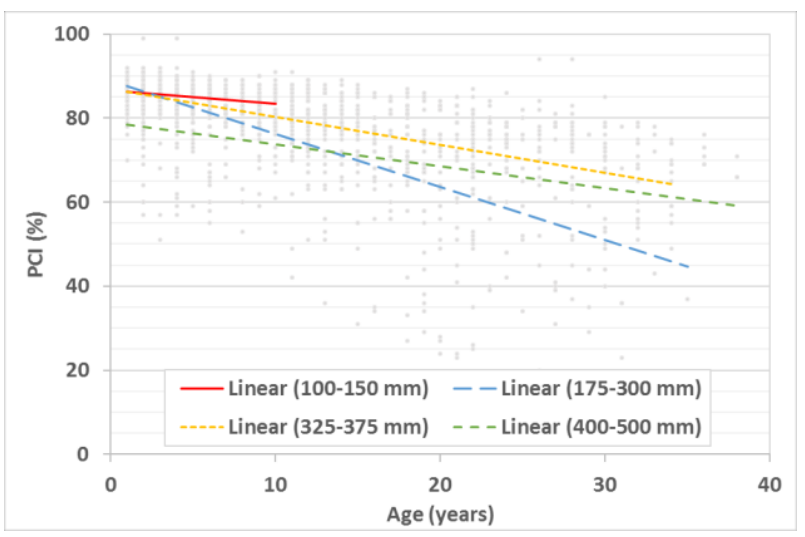

Figure 5. PCI data showing trend lines for different joint spacing

Finally, the data were split by slab thickness; once again indicating a small improvement in life associated with thicker slabs (Figure 6).

When reviewing these plots it must be noted that thickness and panel size are not independent from each other, and that they are a function of the design type (bonded/unbonded).

Review of the IRI data indicates similar trends (Figure 7). Little effect of panel thickness or size is observed for all types.

Considering that PCI is calculated from several parameters, including IRI, it is not surprising that generally similar trends are observed when considering both parameters. 


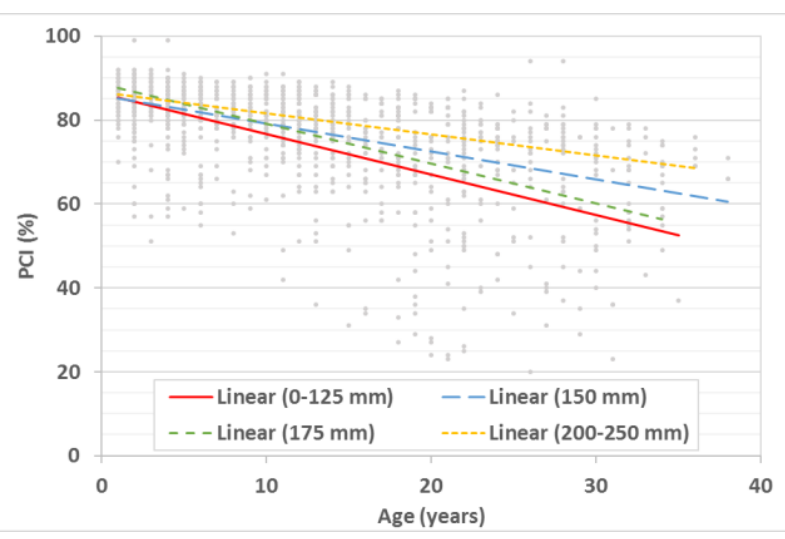

Figure 6. PCI data showing trend lines for different concrete thickness

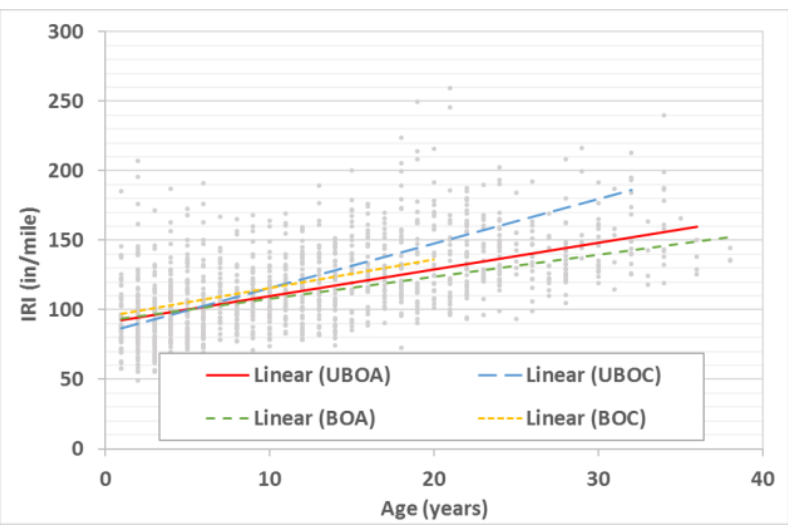

Figure 7. IRI data for all overlays as a function of time

However, a plot of IRI vs PCI (Figure 8) shows a greater spread at greater distress levels, likely due to the variety of mechanisms in play as age increases. Such differences are likely to be reflected in PCI but not necessarily in IRI data. Typical of this are the plots for the BOC systems where PCI deteriorates faster than the other systems, but this is not observed in the IRI plot. IRI may not flag deterioration, while PCI does, indicating that the distress is likely related to factors such as d-cracking or joint deterioration.

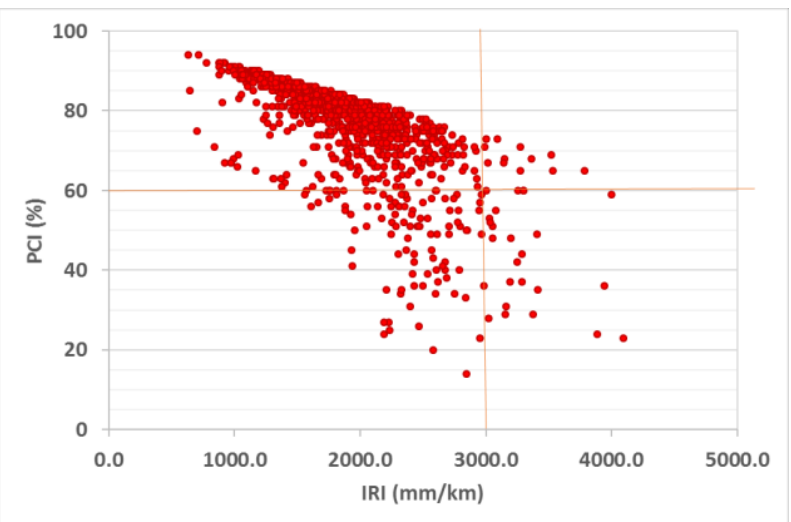

Figure 8. PCI vs IRI data

\section{Closing}

Based on the data available for overlays built in Iowa; service life generally exceeds the 20 -year expectation, averaging 35 years. Unbonded systems tend to perform better than bonded.

If premature materials failures can be prevented, it is likely that life spans well in excess of 40 years can be expected.

Guidance on overlay type selection, design and construction best practices is available at cptechenter.org

\section{References}

1. Taylor, P.C., Harrington, D.H., "Concrete Overlays for Pavement Rehabilitation," International conference on Concrete Repair, Rehabilitation and Retrofitting, ICCRRR, August 2012

2. National Concrete Overlay Explorer, http://overlays.acpa.org/webapps/overlayexplorer/in dex.html

3. Jerod Gross, Dan King, Dale Harrington, Halil Ceylan, Yu-An Chen, Sunghwan Kim, Peter Taylor, and Orhan Kaya, "Concrete Overlay Performance on Iowa's Roadways," Iowa Highway Research Board, Ames, IA, IHRB Project TR-698, July 2017.

4. McGhee, K.H., NCHRP Synthesis of Highway Practice 204: Portland Cement Concrete Resurfacing. National Cooperative Highway Research Program, Washington, DC, 1994.

5. Smith, K., D. Harrington, L. Pierce, P. Ram, and K. Smith., Concrete Pavement Preservation Guide, Second Edition. National Concrete Pavement Technology Center, Iowa State University, Ames, IA., 2014. 